\title{
Estrutura e Organização do Trabalho Infantil em Situação de Rua em Belo Horizonte, MG, Brasil
}

Structure and Organization of Children's Work on the Streets in Belo Horizonte, MG, Brazil

Maria Núbia Alves Cruz

Assistente Social da Prefeitura Municipal de Belo Horizonte Endereço: Av. Afonso Pena, 1212, Centro, CEP 30130-908, Belo Horizonte, MG, Brasil.

E-mail: ncruzœmedicina.ufmg.br

Ada Ávila Assunção

Professora do Programa de Pós-Graduação em Saúde Pública Faculdade de Medicina da Universidade Federal de Minas Gerais Endereço: Av. Alfredo Balena 190 sala 630, Santa Efigênia, CEP 303ı450, Belo Horizonte, MG, Brasil.

E-mail: adavilaœmedicina.ufmg.br

\section{Resumo}

Este artigo analisa a estrutura e as práticas de trabalho infantil em situação de rua, focalizando as estratégias e o papel das famílias. O método utilizado combina técnicas de observação da atividade, entrevistas simultâneas e entrevistas fora do local da atividade. As categorias de interesse para responder à hipótese do estudo foram organizadas, classificadas e analisadas por meio de cartas temáticas. Os resultados mostram a influência das famílias e da comunidade na execução das atividades e a mobilização de estratégias, visando alcançar os objetivos de trabalho. Esse comportamento expressa a aceitação e a participação familiar e da sociedade na estruturação do trabalho infantil. Porém a exposição à violência não é minimizada pela participação dos genitores, tampouco pela constituição de uma suposta rede de solidariedade. Não se vislumbram possibilidades educativas, dadas as condições de trabalho, incompatíveis com a idade dos sujeitos.

Palavras-chave: Trabalho infantil de rua; Estrutura; Família. 


\section{Abstract}

This article analyses the organization and work practices of subjects enrolled in public programs of income transfer, focusing on the strategies developed and on the role of families in placing children and adolescents in street jobs. The qualitative method that was used applied activity observation techniques combined with simultaneous and outside work interviews. Narrative analysis was used based on categories of interest defined to answer the study hypothesis. The results show that there is a direct influence of families and the community on the performance of the activities and that the groups mobilize strategies to achieve their aims. This behavior expresses that the family and society accept and participate in the organization of children's work on the street. However, exposure to violence is not diminished by parents' participation nor by the constitution of a supposed solidarity network. Educational possibilities are not anticipated due to the work conditions, which are incompatible with the subjects' age.

Keywords: Children's Work on the Street; Structure; Family.

\section{Introdução}

A infância ainda não é objeto constituído no discurso científico. Os estudos realizados nas últimas décadas e os debates por eles gerados suscitam articulações das disciplinas e das áreas do conhecimento implicadas. A imaturidade biológica das crianças não permitiria o desenvolvimento de determinadas práticas durante esse ciclo da vida e o reconhecimento das circunstâncias protetoras e favorecedoras da infância seria uma construção social. Nessa direção, a infância é considerada pela sociologia como um componente da cultura e da sociedade e não simplesmente um momento precursor das fases biológicas seguintes (Sirota, 2001; Montandon, 2001). O crescimento físico e a transformação social da criança em adulto não é homogêneo para todos os indivíduos que se encontram numa determinada faixa etária. Ao contrário, é importante lembrar que não existe uma, mas, sim, uma pluralidade de infâncias, as quais são construídas sob relações sociais concretas e as diferenças entre crianças não podem ser negadas. Este artigo trata da infância marcada pelo trabalho.

O trabalho infantil no contexto de rua expõe os sujeitos à violência e ao mundo da marginalidade (Campos e col, 2000; Lusk e Mason, 1993; Marques, 2001; Brasil, 200o; Minayo-Gomez e Meirelles, 1997; Zaluar, 2004). Apesar da magnitude do fenômeno (IBGE, 2001), são raros os estudos com interesse focalizado na estrutura do trabalho praticado pelas crianças.

Vários estudos apontam que as crianças em situação de rua utilizam a maior parte do seu tempo em atividades de trabalho, pedindo esmolas e brincando, com o objetivo de auferir renda para sua própria sobrevivência e da família (Alves e col., 2002; Campos e col., 2000; Menezes e Brasil, 1998; Silva e col., 1998).

Na maioria das vezes, observa-se uma tendência a rotular todos os sujeitos que estão na rua como crianças pobres, com problemas de conduta, inseridas em atividades ilícitas e sem vínculos familiares (Lusk e Mason, 1993; Maciel e col, 1997). Como será descrito a seguir, existe uma diversidade relevante de situações que distinguem os sujeitos, pela estruturação das estratégias de trabalho, pela participação familiar e pelos tipos de atividades desenvolvidas na rua. 


\section{Procedimentos Metodológicos}

\section{Delineamento do estudo}

Este é um estudo observacional de caráter exploratório, que combina técnicas de observação em campo com entrevistas. A estratégia adotada visa retratar a perspectiva dos participantes diante do fenômeno que marca suas vidas e seus comportamentos (Godoy, 1995; Lüdke e André, 1986; Triviños, 1987). Buscou-se construir conhecimentos sobre a estrutura do trabalho infantil, por isso os vai-e-vens na aplicação das técnicas ao longo da investigação, a partir de contato direto em situações nas quais o fenômeno é produzido.

Trabalho infantil é qualquer atividade laborativa regular, remunerada ou não, domiciliar ou não, realizada por crianças e adolescentes menores de 16 anos. 0 trabalho infantil em situação de rua consiste num modelo específico, em que crianças e adolescentes são caracterizados, principalmente por sua presença, durante um período ou mais do dia, nas ruas. Nas ruas, os pequenos trabalhadores implementam o conjunto das estratégias de sobrevivência apreendidas no âmbito da família, com o objetivo claro de garantir uma renda mínima, às vezes a única fonte de que os familiares dispõem (Alves e col., 1999).

\section{Os sujeitos do estudo e os cuidados éticos}

Os sujeitos envolvidos nesta pesquisa são crianças e adolescentes trabalhando em situação de rua e inscritos em programas públicos de transferência de renda.

Seis equipes de trabalho foram encontradas aleatoriamente, trabalhando nas ruas do centro da cidade. Três equipes foram identificadas nos registros de ocorrência de trabalho infantil nos arquivos do Programa Bolsa Escola Municipal de Belo Horizonte (BEM-BH). Do conjunto de nove equipes inicialmente selecionadas, três foram excluídas: a primeira porque a mãe não consentiu; e as outras duas, apesar de identificadas, por não terem sido encontradas trabalhando no local referido na ficha de acompanhamento do BEMBH (Figura 1).

\section{Figura I - Diagrama explicativo dos procedimentos adotados para seleção das equipes}

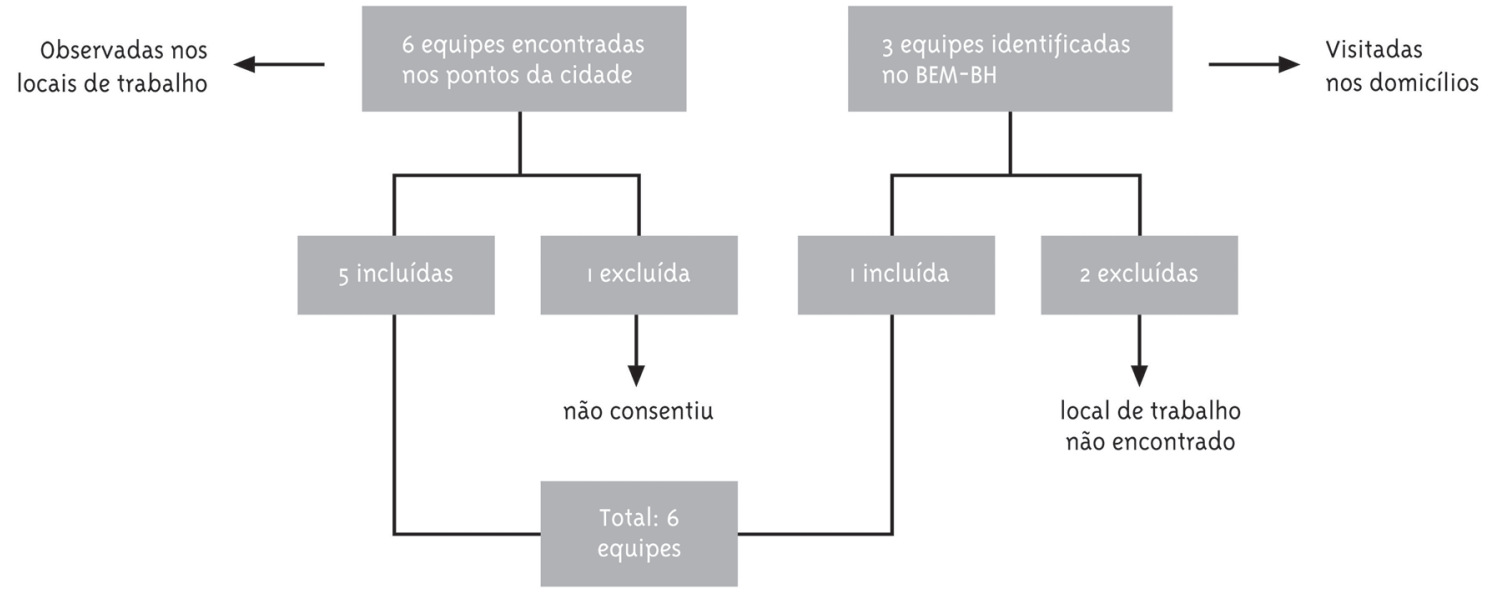

Ao todo, seis equipes de trabalho infantil em situação de rua foram observadas e entrevistadas. Todas representam dez famílias cujos membros foram entrevistados em uma etapa posterior à etapa das observações das equipes em situação de rua. As equipes $\mathbf{C}$, D e F contam com mais de uma família em sua base.
Cinco famílias são do tipo monoparental feminina, composta de mãe e seus dependentes. As outras cinco são do tipo biparental, ou seja, contam com a presença da mãe e do pai. Duas famílias biparentais são ampliadas pela presença dos filhos de relações anteriores (Tabela 1). 
Tabela I - Perfil das equipes estudadas

\begin{tabular}{|c|c|c|c|c|c|}
\hline equipe e atividade (número) & tipo de família & no de membros da família & regime de trabalho & adulto cuidador & horário de trabalho \\
\hline \multicolumn{6}{|l|}{$A-$ vende suco (3) } \\
\hline família I & BPA & 7 & familiar & presente & diurno \\
\hline \multicolumn{6}{|l|}{$B-$ vende chicletes (4) } \\
\hline família 2 & BPA & 8 & familiar & presente & noturno \\
\hline \multicolumn{6}{|l|}{ C-cata papel (2) } \\
\hline família 3 & MPF & 5 & laços de vizinhança & ausente & diurno \\
\hline família 4 & MPF & 3 & & & \\
\hline \multicolumn{6}{|l|}{ D-calibra pneus (2) } \\
\hline família 5 & $\mathrm{BP}$ & 5 & laços de vizinhança & ausente & diurno \\
\hline família 6 & $\mathrm{BP}$ & 6 & & & \\
\hline \multicolumn{6}{|l|}{ E-malabares (3) } \\
\hline família 7 & MPF & 7 & familiar & presente & diurno/ noturno \\
\hline \multicolumn{6}{|l|}{ F-malabares (3) } \\
\hline família 8 & MPF & 5 & laços de vizinhança & ausente & diurno \\
\hline família 9 & MPF & 8 & & & \\
\hline família ı & $\mathrm{BP}$ & 8 & & & \\
\hline
\end{tabular}

BPA-Biparental Ampliada BP-Biparental MPF Monoparental Feminina

Foram entrevistadas e observadas durante o trabalho, dezessete crianças e adolescentes na faixa etária de oito a dezessete anos.

Primeiramente, os indivíduos foram esclarecidos sobre os objetivos e os procedimentos do estudo e, concordando em participar, assinaram um termo de consentimento livre e esclarecido. Este estudo, respeitando os cuidados éticos necessários, teve seus objetivos e técnicas avaliados e foi aprovado pelo Comitê de Ética em Pesquisa da Universidade Federal de Minas Gerais.

\section{Coleta e análise de dados}

Inicialmente, foram exploradas as ruas do centro da cidade, com a finalidade de se identificar crianças em situação de trabalho. Após a identificação das equipes, buscou-se seu possível registro nos arquivos do Programa Bolsa Escola de Belo Horizonte (BEM-BH) e do Programa Bolsa Família. As dez famílias a que as crianças pertenciam foram inicialmente selecionadas e convocadas por carta ou telefone para entrevistas, que ocorreram em seus domicílios (duas), ou nos espaços da Prefeitura (oito).

\section{Observações diretas do trabalho e entrevistas simul- tâneas}

Foram realizadas observações com entrevistas simultâneas, que totalizaram vinte e cinco horas. Nesses momentos, nos próprios locais de trabalho, foram observados aspectos relativos à presença do núcleo familiar, aos horários de trabalho, ao conteúdo do diálogo com o público, às estratégias de venda, ao vestuário e aos instrumentos de trabalho.

Os resultados das observações foram analisados, buscando-se descrever a repartição de tarefas no seio da equipe e a participação da família no coletivo de trabalho, além das atribuições de cada membro e as estratégias de venda e de relacionamento com a comunidade.

Essa experiência retoma os desafios da pesquisa envolvendo crianças de rua, pois as observações no espaço de rua resultaram no registro de inúmeros comportamentos estereotipados, uma vez que as crianças sabiam que estavam sendo observadas. Para contornar as dificuldades, antes das observações de campo, procurou-se uma aproximação com os sujeitos a fim de apresentar os objetivos pretendidos e estabelecer elos de confiança. Durante as observações, ao perce- 
ber o desconforto da criança pela sua presença, a pesquisadora imediatamente deslocava-se para outro ponto da rua guardando uma distância que perturbasse o menos possível o andamento das atividades dos pequenos trabalhadores.

\section{Entrevistas com as famílias}

As questões semidirigidas nas entrevistas com as famílias tiveram como base os resultados das observações diretas do trabalho infantil, visando sua explicitação das condições objetivas que explicariam a prática de inserção precoce dos filhos no trabalho.

As questões abertas, acrescidas do estímulo à fala livre dos sujeitos, permitiram apreender os aspectos subjetivos que estariam na origem e na reprodução do trabalho infantil em cada família específica. Assim, as aparentes contradições observadas foram tratadas e outros dados relevantes para a compreensão do objeto foram registrados. A totalidade das entrevistas com as famílias das crianças trabalhadoras, com duração de vinte horas e quinze minutos, foi gravada após o consentimento dos sujeitos e foram transcritas pelas pesquisadoras.

\section{A análise dos dados}

Na etapa de análise, os dados originados das observações e entrevistas foram separados, levando-se em conta a equipe de trabalho e o núcleo familiar. 0 material gerado foi analisado em seu conteúdo, em torno dos temas elaborados após as primeiras leituras, e classificado em dois grandes grupos: equipe organizada sob regime familiar e equipe organizada por laços de vizinhança e amizade.

As leituras permitiram a elaboração de cartas temáticas, tendo como base as narrativas dos sujeitos entrevistados. Buscou-se destacar o determinante econômico, a composição e a divisão do trabalho nas equipes, as estratégias da participação familiar, a tomada de decisão sobre o envio dos filhos ao trabalho, a tradição familiar na prática do trabalho infantil e as características dos pares no caso do trabalho em equipe por laços de vizinhança e amizade.

Observando-se as ações, bem como as verbalizações das crianças, foi possível fazer uma aproximação da lógica interna da atividade, ou seja, aos poucos, evidenciaram-se não só as condições reais do trabalho na rua, situadas em um tempo e lugar bem definidos, como também o pequeno trabalhador, com os seus valores e, ainda, as regras, a divisão das tarefas, as relações com os diferentes membros da equipe e da comunidade.

A análise dos componentes do trabalho em situação de rua, obtidos nas observações e entrevistas, articulada à análise da narrativa livre da história do trabalho de cada um dos membros do núcleo familiar permitiu tecer a rede de fatores, subjetivos ou não, envolvidos na prática estudada nesta investigação.

\section{Reflexão sobre as estratégias e formas de organização do trabalho infantil}

As atividades das crianças que trabalham nas ruas são organizadas coletivamente em equipes familiares ou equipes organizadas por laços de vizinhança. As equipes estudadas nesta pesquisa vendem produtos, prestam serviços, praticam malabares ou catam papel (Tabela 2).

\section{Tabela 2 - Estrutura do trabalho infantil segundo o tipo de equipe}

\begin{tabular}{|c|c|c|c|c|}
\hline \multirow{3}{*}{ produção } & \multicolumn{4}{|c|}{ Equipe } \\
\hline & \multicolumn{2}{|c|}{ familiar } & \multicolumn{2}{|c|}{ laços de vizinhança } \\
\hline & Fixa & móvel & fixa & móvel \\
\hline venda & equipe suco & $\ldots$ & $\ldots$ & $\ldots$ \\
\hline serviços & $\cdots$ & $\cdots$ & equipe pneus & $\ldots$ \\
\hline malabares & $\ldots$ & equipe malabares I & $\ldots$ & equipe malabares 2 \\
\hline catador de papel & $\ldots$ & $\ldots$ & $\ldots$ & equipe catador de papel \\
\hline
\end{tabular}




\section{Os riscos vivenciados em situação de trabalho de rua}

Em todas as equipes observadas, as crianças que trabalham na rua ficam expostas às adversidades, às intempéries e são vítimas da violência urbana. A título de exemplo, uma mãe narra que:

Tinha um cara seguindo eles, sempre olhando para eles. Passava com o carro em volta deles, sempre olhando. Aí, teve um que falou uma palavra com eles, uma palavra obscena. Ele ficou com medo, correu para onde eu estava (...) (S, mãe)

Expostos à violência e trabalhando, as crianças são ameaçadas tanto pelos desconhecidos como pelos seus pares, como mostra o depoimento dessa criança:

No meio de camelô você não pode roubar; se você roubou, você roubou a todos. Você apanha de todo mundo. Aí você aprende a não roubar e a ficar no seu canto, entendeu? (M, 14 anos)

O depoimento de uma adolescente é claro quanto aos riscos impostos pela atividade:

Acidente eu sofri quando eu tinha de oito para nove anos, que eu fui atropelada, eu estava com meu pai... A gente estava atravessando, aí o cara estava bêbado e avançou o sinal (...) Fiquei cinco dias em coma, dentro do CTI (...) Quando eu acordei, não sabia de mais nada, para mim foi tudo um sonho! (L, 17 anos)

A escola de rua possibilita, nos dizeres de Lusk e Mason (1993), entre outras coisas, a socialização de crianças e adolescentes dentro de um estilo de vida predatório e delinqüente. As crianças ficam expostas aos perigos da sociedade de rua, que é formada por pessoas em trânsito, gangues, polícia, criminosos e adultos prontos para explorá-los (Zaluar, 2004) como revela uma das mães:

Uns três meninos pegaram ele e bateu nele, tomouo bastão, tomou o boné. Estavam caçando dinheiro, ele não tinha dinheiro, veio embora. Era o tempo que ele estava trabalhando na Milton Campos (...). Ele tomava conta de carro e estava começando a aprender a fazer isto (...) (M, mãe)
No caso relatado, vê-se que as famílias declaramse conscientes dos riscos a que estão expostas as crianças. Outra mãe entrevistada enumera as diversas agressões que fazem parte do cotidiano de trabalho de seus filhos:

Teve uma vez que nós estávamos catando latinha (...) Ele foi atravessar a rua e o carro bateu nele. Agressão na rua, menino bater, tomar o dinheiro deles muitas vezes já aconteceu. Atéesse menino de 16 anos, já bateram nele, tomou o dinheiro(...) 0 moço da portaria chutou meu menino de 16 anos, bateu nele! (S, mãe)

\section{Modalidades de organização e estratégias vinculadas ao trabalho de rua}

As crianças que trabalham com vizinhos e amigos, em atividades de jogos de malabares, não contam com o aparato protetor que a família proporciona, como nos casos de equipes familiares. Os dados coletados indicam que as equipes de regime familiar de trabalho infantil são mais favorecidas, quando comparadas às equipes por vizinhança, no que se refere à consolidação de vínculos permanentes com a comunidade. Excetuando a equipe que presta serviços calibrando pneus em um posto de gasolina, as outras equipes organizadas sob laços de vizinhança não possuem local fixo de trabalho.

Duas equipes de trabalho em regime familiar possuem local fixo de trabalho e contam com suportes na comunidade: As pessoas já sabem, conhecem a gente... (F, 15 anos), diferentemente das duas equipes formadas por laços de vizinhança que são nômades e, portanto, menos protegidas, pois não contam com o apoio da comunidade tampouco de familiares: Não, nós não conhecemos o pessoal, só aquele ali, que toma conta de carro. (D, 10 anos).

É usual a implementação de estratégias junto à comunidade quando as crianças trabalham em locais fixos evidenciando, nos casos estudados, que o trabalho infantil em situação de rua é estruturado, estando presentes, inclusive, laços consolidados com os outros trabalhadores e com os próprios clientes: 
O pessoal que já pega na minha mão, fiado. Aí, na hora, um fala assim: amanhã você pega. Aí eu falo: tá beleza, amanhã eu pego com você... Tem uns que falam: me dá duas aí, que eu estou atrasado, tenho que pegar o ônibus. Eu já conheço, eu falo: pode pegar aí! (M, 14 anos)

Pontos de apoio são estabelecidos para o uso de banheiros, para repouso ou conforto, como lavar o rosto, tomar água: Fui ao banheiro e tomar água. Aproveitei e lavei o rosto, que estava suado. Uso o banheiro daquele prédio, só quando preciso ( $\mathrm{F}, 15$ anos).

A rede de apoio, além da logística, é fonte de informações-chave para o desenvolvimento da atividade, como revela um dos adolescentes: $\varepsilon u$ fico sabendo da programação das casas (noturnas) porque os porteiros me falam, aínós decidimos se trabalhamos ou não na segunda ou terça-feira ( $\mathrm{L}, 15$ anos). A presença de uma rede de proteção lembra os achados de Alves e col. (2002), que estudaram as atividades de crianças em situação de rua, em Porto Alegre, concluindo que o contexto da rua pode oferecer segurança.

Além do caráter familiar do trabalho de rua, o tipo de atividade também concorre para fixar a equipe de trabalho. Viu-se que, na venda de produtos, as crianças elaboram estratégias junto aos clientes, a outros trabalhadores e junto à comunidade, constituindo relações de confiança e de solidariedade, como mostra o depoimento de uma criança: Usamos o banheiro e tomamos água no posto de gasolina. Aqui todos são amigos e meu pai trabalha aqui, como vigia, à noite (M, 14 anos). Já as duas equipes que praticam malabares e a equipe de catadores de papel são nômades. As duas equipes que vendem produtos e outra que presta serviços são fixadas em pontos determinados da cidade: porta de casas noturnas, ruas do centro da cidade e posto de gasolina.

O desenvolvimento da atividade de rua requer a elaboração de estratégias variadas, como a elaboração de scripts para atrair o cliente, escolha dos melhores dias para trabalhar, distribuição geográfica dos membros da equipe nos pontos de venda, controle intraequipe. Segundo Alberto (200o), Aptekar (1994), Ashagrie (1998) e Marques (2001) é comum o uso de estratégias pelas crianças em situação de rua para obter algum tipo de auxílio em dinheiro, como mostra o extrato dos depoimentos:
É nesta calçada, vira, vira até terminar aqui. Depois eu passo para o outro lado da rua, atravesso aí, e por aí vai (...) (W, 13 anos)

Tem vez que nós trabalhamos dia sim, dia não. Porque nós trabalhamos em época de calor, né? (M, 14 anos)

Faz parte da estrutura do trabalho no contexto de rua a participação de adultos nas equipes de trabalho. Observa-se que, nas equipes familiares, o coletivo de trabalho infantil em situação de rua não é formado exclusivamente por crianças e adolescentes, podendo contar com a presença de outros membros da família: Meu pai vem, ele vende água e cerveja e toma conta da gente! (L, 15 anos).

Outra equipe familiar vende artigos industrializados, mas pode variar na oferta do produto, a depender da época do ano, como se verá. E outra fabrica o produto que será oferecido pelas crianças na rua. Em ambas, percebe-se um planejamento interno e uma repartição das atividades entre os familiares membros da equipe: Quando ele (pai) não pode vir, eu venho para tomar conta dos meninos! (L, 17 anos). Os pais assumem a coordenação e o planejamento das atividades: Então meu papel é organizar as saídas! (L, pai); participando diretamente da atividade, delegando responsabilidades e orientando os filhos: Oriento, porque eu já trabalhei na rua, eu vejo como é. Eu ensino em casa (A, mãe).

Pode-se afirmar que a organização do trabalho infantil em situação de rua é estruturada, uma vez que inclui controle e uma espécie de contabilidade: $\varepsilon s s a$ semana foi boa para nós, nós tiramos 258 reais, eu somo tudo, ali no caderno! (B, mãe). 0 planejamento das ações leva em conta, inclusive, a sazonalidade da procura pelo produto, que pode ser remarcada nos extratos a seguir:

A gente muda (a mercadoria) de acordo com o dia, com o tempo. No carnaval, como não sai muito chiclete e bala, então a gente resolveu levar fantasia, porque no carnaval eles procuram fantasia. A gente levou espuma, anel, anel que acende sozinho (...) (L, 15 anos)

Nós levamos o resto da mercadoria que tínhamos, aívendemos o resto, meu pai trabalhou com o carrinho de cerveja. (L, 17 anos) 


\section{A divisão etária do trabalho, as "ações edu- cativas" e a hierarquia desempenhada pelos pais ou vizinhos}

Cada etapa do processo de trabalho é atribuída a um membro específico do núcleo familiar. Por exemplo, na família A, na atividade de venda ambulante de suco, o pai e a mãe preparam o produto com a ajuda do tio, fazem o envasamento em embalagens plásticas. A mãe é responsável pela higienização da caixa de isopor e pelo acondicionamento detalhado das embalagens do suco em seu interior, visando garantir as condições ideais de transporte e a qualidade do produto a ser vendido pelas crianças: "Um produto, tem que estar tudo limpinho, inclusive, eu lavo as caixas quase todos os dias, os panos que colocam (...)" (A, mãe).

A família de $\mathrm{B}$, de maneira semelhante à família $\mathrm{A}$, destina às crianças a venda de produto, feijão tropeiro acondicionado em marmitex, fabricado pela mãe: No ano passado, por exemplo, nós trabalhamos com marmitex. Vendi feijão tropeiro, mas vendi demais (...) Eu fazia e eles vendiam, eu preparava as marmitas, fechava e eles entregavam! (B, mãe).

Nas famílias estudadas, a participação dos pais na orientação dos filhos é freqüente, ensinando e transmitindo valores e normas de comportamento, reforçando a tese de Rizzini (2002) e Marques (2001) de que a família se constitui como locus de formação para o trabalho:

Na rua ele (o pai) olha a gente, na rua ele já conhece os camelôs (...) Ele mostra a gente a rua, por onde a gente tem que passar, para a gente não ficar perdido (...) Ele só fala: tenta ser o mais educado possível, para não perder os clientes. (M, 14 anos)

Para além da determinação econômica, o valor atribuído ao princípio educativo do trabalho contribui para a naturalização dessa prática no seio das famílias pobres e justifica o estímulo dos pais ao trabalho das crianças. A tradição do trabalho como estratégia de formação dos filhos fundamenta-se na noção de trabalho como veículo da construção de sociabilidade e suporte fundamental de pertencimento.

A crença indiscriminada na dignidade do trabalho (Campos e Alverga, 2001) e um discurso de justificação da inserção precoce no trabalho (Campos e Francischini, 2003) servem para minimizar os riscos vivenciados no trabalho em situação de rua. Como se vê no extrato reproduzido abaixo, as famílias são conscientes dos riscos e tentam orientar os filhos para escaparem de seus efeitos:

Falo com ele para ficar sempre mais ativo, e só ir com pessoa de boa família (...) Aí eu dou muito conselho para ele. Falo para não guardar nada que os outros pedirem para guardar. Pedir para dar um recado lá na frente, fulano mandou, não vai dar. Não dá, nem guarda nada de ninguém (...) para guardar na rua, esconder de alguma polícia (...) (M, mãe)

Se nas equipes familiares a divisão do trabalho reporta-se aos papéis dos seus membros (pai, mãe e filho), nas equipes organizadas por laços de vizinhança e amizade, nota-se a existência de uma hierarquia de funções baseada na idade de seus membros, como ilustra o extrato a seguir: $O$ mais velho comanda os outros, uai! Ele fazendo gracinha, chamo ele para fazer, ele não quer. Só porque não quero deixar ele ficar na segunda fila (D, 11 anos).

A hierarquia etária também está presente na atribuição de responsabilidades referentes ao controle dos ganhos: $O$ dinheiro de papel fica comigo, as moedas ele (oito anos) guarda, depois nós dividimos para os três (J, 14 anos).

A figura do adulto cuidador foi citada por crianças de três equipes entrevistadas: Eu não venho sozinha, minha irmã de 16 anos também vem. Ela foi tomar água, mas vai voltar! (F, 14 anos); “ (D, 11 anos). 0 adulto cuidador pode participar diretamente do trabalho, ou apenas proteger e vigiar os outros membros mais novos: Meu menino mais velho, de 16 anos, vai com eles. $\varepsilon$ para tomar conta deles, ele tem vergonha, assim de pedir (dinheiro) (S, mãe).

$\mathrm{O}$ adulto cuidador pode ser externo ao núcleo familiar, por exemplo, um camelô, evidenciando elos de pertencimento a grupos específicos. Observa-se, no contexto estudado, que a mediação com o adulto cuidador fora do núcleo familiar é realizada pelo pai, conforme o seu relato: $\bar{\varepsilon}$ um filho de um amigo e tem proteção, todo mundo ali protege (...) com 25 anos de rua, tem um clube de amizade muito grande, e eles (filhos) estão ali naquele ambiente que todo mundo conhece! (L, pai). 
Durante os períodos de observação não foi notada a presença do adulto cuidador nas equipes organizadas sob laços de vizinhança, apesar de as crianças mencionarem que o irmão ou a mãe estava por perto, ou tinha vindo trazer o material ou estariam esperando por eles para o retorno às suas casas.

\section{As modalidades do trabalho, sistema de turnos, e o trato da "clientela"}

Entre as seis equipes estudadas em situação de trabalho, duas praticam atividade de malabares, associada a atos de mendicância legitimados e reconhecidos socialmente em cada ato do pedinte (Serrano, 2004), como se verá nos depoimentos das crianças. Segundo o dicionário Houaiss da Língua Portuguesa, a palavra mendicância deriva do latim mendícus e caracteriza aquele que pede esmola e vive da caridade alheia. Podese mencionar também a mendicância profissional, caracterizada pela atividade de pessoas que usam sua condição de miséria para sensibilizar a caridade pública e obter sustento (Stoffels, 1997 citado por Serrano, 2004).

Quando a atividade de rua é de mendicância, ao contrário das atividades de venda ou de pequenos serviços em regime familiar, as estratégias de relação com o transeunte mostraram-se frágeis e pouco elaboradas.

Sem poder afirmar que a diferença no trato com o cliente seria efeito da diferença da própria atividade de vender ou de mendigar, nota-se distinção evidente na estratégia de contato com o cidadão quando, em vez de cliente, procura-se o benevolente. Essa lógica da estruturação do trabalho de rua parece explicar o tom espetacular da atividade de jogos de malabares, evidenciada nas acrobacias sobre o corpo dos outros, no uso de fogos e nas pinturas do rosto com o objetivo de atrair atenção.

Para crianças e adolescentes, o jogo de malabares associado ao recolhimento de dinheiro não é considerado ato de mendicância, mas uma prática de trabalho, como revela uma das crianças envolvidas nesse tipo de atividade: Isso não é esmola, não. É a mesma coisa de um teatro! (D, 11 anos). Embora essas crianças estudadas usem de artifícios como jogos de malabares para obter renda, Alves e col. (2002), Marques (2001) e Lusk e Mason (1993) referem-se ao ato de esmolar como um trabalho típico de crianças em situação de rua.
Ao contrário das crianças, uma das mães é categórica ao afirmar tratar-se de mendicância. Nos seus dizeres: Ah, eu acho que aquilo ali não é serviço, não. Se fosse serviço tinha um lugar certo, uma firma (...) Alguém que pagasse eles por mês, para fazer aquilo (...) (S, mãe).

Marques (2001) destaca o uso de brincadeiras, piadas, rimas e a adoção de postura respeitosa e educada como estratégia comum entre os pequenos trabalhadores, com o intuito de convencer o cliente.

Quando a atividade de pedinte associa-se ao jogo de malabares, a criança apresenta-se e aguarda a reação do cliente, mantendo-se numa posição passiva. Observa-se diferentes reações dos clientes diante da criança: ora aprovam a atividade com palavras de incentivo e doação de dinheiro; ora rejeitam e constrangem os sujeitos, sem utilizarem rodeios, fechando os vidros dos carros, deixando claro ao pedinte a negativa da doação. As crianças explicam: $\varepsilon$ que (os motoristas) ficam com medo!(D, 11 anos); Tem umas que ficam com medo porque acham que a gente tá indo roubar! (L, 17 anos). Nas equipes dos sujeitos que faziam jogos de malabares ou catavam papel, a participação da família mostrou-se discreta. As mães tentam acompanhar a atividade e conhecer as condições nas quais os filhos estão trabalhando, porém a precariedade de determinadas atividades parece levá-las a abandonar esse propósito, desestimuladas pela dureza da rua, como revelou uma das mães entrevistadas: $\varepsilon$ u fui, uma vez, quando ele estava aprendendo (...) eu achei muito cansativo! (M, mãe).

As atividades de malabares exigem força física e provocam rígida repartição das tarefas baseada na estatura. Assim, duas crianças maiores e mais fortes sempre sustentam outra, menor no tamanho e no peso. Na atividade de catar papel, as funções, de maneira semelhante, obedecem à mesma lógica, quando o material a ser recolhido está acondicionado num contêiner que não permite a entrada de um adulto devido à dimensão estreita de sua abertura, sendo possível apenas a uma criança de baixa estatura recolher o material. Evidencia-se, no relato a seguir, esse componente do trabalho infantil em situação de rua: crianças e adolescentes executam atividades inexeqüíveis por adultos (Dias e col., 2002; Rizzini, 2002): Ele é pequeno, aí ele entra e pega (o papel), eu pego e dobro e arrumo (L, 10 anos); Nós somos grandes, aínós não ganhamos, 
não. Nós pedimos, mas quem ganha mais é o B" (de oito anos) (J, 14 anos).

A divisão do trabalho intra-equipe favorece o alcance dos objetivos propostos e leva em conta a carga física do trabalho. Os membros da equipe trabalhando na rua podem alternar de função, como revela a adolescente entrevistada: "Não, não fico (cansada). Quando eu estou cansada troco com minha irmã e descanso!" (F, 14 anos).

Viu-se que as crianças e adolescentes, quando trabalham na rua, desenvolvem estratégias variadas para garantir os objetivos de trabalho, que podem ser mais ou menos elaboradas, a depender da atividade desenvolvida, da familiaridade e do tempo de trabalho no local, convergente com estudo realizado por Alberto (200o), na cidade de João Pessoa. As possíveis variações envolvem os trajetos percorridos, a abordagem do cliente, a relação com a rede de amigos, com a polícia e com outros trabalhadores de rua. Uma mesma criança usa estratégias diferentes para abordar clientes de acordo com a idade, gênero, nível de intimidade ou conhecimento, e preferência sexual do cliente. A elaboração de estratégias complexas requer habilidade, seja criando ou memorizando scripts para convencer os clientes seja memorizando suas fisionomias, realizando cálculos matemáticos, ou fazendo negociações, como relatam as crianças envolvidas com atividades de venda:

Quando eu termino, guardo minha caixa e passo, cobrando todo mundo. Aí, na hora, que um fala amanhã você pega, aí eu falo: tá beleza, amanhãeu pego com você! (M, 14 anos)

Troco com o dono da festa (...) Troco chiclete por convite. Aí eu vendo o convite a oito reais e dá direito a consumação! (L, 15 anos)

Os adolescentes criam scripts diferenciados de acordo com as características do cliente, como mostra o depoimento de L: Quando é homossexual eu falo: trident sem açúcar, não dá cárie, não engorda, deixa os beijos gostosos, refresca o pensamento dos gatos. Combina com você e com a boate Josefine! (L, 17anos). A adolescente completa explicando que: Se éuma pessoa de mais idade, eu digo: senhora compra um chiclete! (L, 17 anos).

Quando a atividade está associada à mendicância, a apresentação das crianças, a organização e o conteú- do do trabalho mudam. Observa-se, no grupo de crianças e adolescentes que trabalham com jogos de malabares e cata de papel, que a aparência é de abandono e a higiene, precária. São características mencionadas por Silva e col. (1998) e Alves e col. (2002) como associadas ao exercício de tarefas humildes, como 'esmolar' e 'engraxar'. De acordo com Teves (1999), a imagem corporal descuidada compromete a auto-estima dos sujeitos.

\section{Trabalho de meninos, trabalho de meninas}

Sobre a prevalência de meninos (quinze meninos e duas meninas), os resultados são convergentes com a literatura consultada. Para Aptekar (1989) e Maciel e col. (1997) uma razão plausível para a segregação por gênero é a inserção precoce das meninas no trabalho doméstico, impedindo a ida para as ruas. Entre 2189 crianças do Programa Bolsa-Escola de Belo Horizonte que relataram algum tipo de trabalho, 1357 (62\%) eram homens e 832 (38\%), mulheres. Nesse grupo, mais da metade (448 meninas) estava trabalhando em tarefas domésticas (Prefeitura de Belo Horizonte, 2004).

No entanto, a repartição das crianças trabalhadoras por ocupação não poupa as meninas do trabalho em situação de rua. A Organização Internacional do Trabalho revela que a proporção de meninas trabalhando à noite e durante a madrugada, no comércio informal, é consideravelmente maior do que as dos meninos, correspondendo a $27 \%$ e $10 \%$, respectivamente (Ashagrie, 1998).

No grupo pesquisado neste estudo, as meninas implementam estratégias de sedução para sensibilizar os clientes: Para os outros ficarem mais caídos assim em você, gostar mais de você, eu vou inventarum versinho (...) aí ele falou: eu só compro da mocinha, porque ela emociona a gente, ela fala um versinho! (L, 17 anos).

A estratégia de tentar mobilizar o sentimento do cliente pode ser praticada pelas crianças do sexo feminino, como assinala um dos meninos entrevistados: Eu não sou como minha irmã, não. Minha irmã fala, eu só ofereço o chiclete. (L, 15 anos).

O uso de estratégias de trabalho diferenciadas segundo gênero também foi assinalado em pesquisas realizadas com crianças em situação de rua de Porto Alegre (Alves e col., 2002). A divisão de trabalho intraequipe é determinada pelo gênero, como revela o de- 
poimento de uma criança: Porque ela é menina, mulher, ela sobe em cima de nós! (D, 11 anos). Outra diferença quanto ao gênero é a preocupação diferenciada das famílias com a proteção das meninas, como revelam os depoimentos das mães: Com ela eu preocupo mais, porque ela é mulher, merecia ficar em casa, ajudando (...) (S, mãe). Ou: Trabalho o dia inteiro. Ele fica em casa só e a irmã fica no Projeto (L, mãe).

\section{Considerações Finais}

É possível afirmar, no contexto deste estudo, que o trabalho infantil em situação de rua organiza-se em equipes de trabalho, requisitando seus membros na própria família ou no grupo de vizinhança ou de amigos. A família tem relevante participação nas atividades desenvolvidas pelas crianças, cumprindo papéis distintos na repartição de tarefas, no planejamento e desenvolvimento do trabalho. A participação familiar parece favorecer as crianças que trabalham sob esse regime, contribuindo na elaboração de estratégias e na divisão de tarefas, em que cada membro assume responsabilidades distintas. Nas equipes familiares, a carga física da atividade pode ser amenizada pela alternância de funções e as famílias proporcionam a formação de valores e normas de comportamentos para a lida com o trabalho, confirmando as teses de Campos e col. (200o), de que essas aquisições no seio familiar contribuem para a construção de estratégias de sobrevivência na rua.

Para alcançar os objetivos da atividade, as crianças e suas famílias desenvolvem estratégias junto à comunidade e aos clientes. As estratégias são expressas pela constituição de redes de apoio junto aos trabalhadores e moradores dos locais de trabalho, por locais fixos de trabalho, pela intermediação familiar para identificação de possíveis adultos cuidadores e pela formação de laços com os clientes.

No que se refere ao gênero, a família e as meninas têm preocupações e estratégias diferenciadas. As famílias demonstram maior preocupação com as crianças do sexo feminino e as meninas mobilizam a emoção do cliente, visando alcançar os objetivos da atividade. Os resultados sugerem, ainda, que o tipo de atividade também concorre para fixar a equipe de trabalho e para obter o apoio da comunidade. As atividades mais precarizadas são nômades, com frágil par- ticipação familiar e menos favorecidas no que se refere à consolidação de laços com a comunidade e com os clientes. Para compensar a ausência de apoio comunitário e familiar, as equipes organizam-se sob hierarquia intra-equipe, com base na idade e na estatura de seus membros.

Em suma, pode-se afirmar que a exposição a constrangimentos, riscos e violências presentes no trabalho infantil em situação de rua independe do tipo de equipe, se familiar ou não. Observou-se também que a constituição de redes de apoio e os ensinamentos familiares não conseguem contornar o ambiente desfavorável e nocivo presente na rua, ou seja, não se vislumbram possibilidades educativas e sociais nesse contexto.

\section{Referências}

ALBERTO, M. F. P. A situação da criança trabalhadora no mercado informal em João Pessoa. Política \& Trabalho, João Pessoa, v. 6, p. 41-54, 2000.

ALVES, P. B. et al. A construção de uma metodologia observacional para o estudo de crianças em situação de rua: criando um manual de codificação de atividades cotidianas. Estudos de Psicologia, Campinas, v. 4, n. 2, p. 289-310, 1999.

ALVES, P. B. et al. Atividades cotidianas de crianças em situação de rua. Psicologia: Teoria e Pesquisa, Brasília, v. 18, n. 3, p. 305-414, 2002.

APTEKAR, L. Characteristics of the street children of Colombia. Child Abuse \& Neglect, Washington, n. 13, v. 3, p. 427-437, 1989.

APTEKAR, L. Street children in the developing world: a review of their condition. Cross-Cultural Research, Washington, v. 28, p. 195-224, 1994.

ASHAGRIE, B. K. Statistics on working children and hazardous child labor in brief. Geneva: International Labour Office, 1998.

BRASIL. Ministério do Trabalho e Emprego. Trabalho precoce: saúde em risco. Brasília, DF, 2000.

CAMPOS, H. R; ALVERGA, A. R. Trabalho infantil e ideologia: contribuição ao estudo da crença indiscriminada na dignidade do trabalho. Estudos de Psicologia, Natal, v. 6, n. 2, p. 227-233, 2001. 
CAMPOS, H. R.; FRANCISCHINI, R. Trabalho infantil produtivo e desenvolvimento humano. Psicologia em Estudo, Maringá, v. 8, n. 1, p. 119-129, 2003.

CAMPOS, T. N.; DEL PRETTE, Z. A. P.; DEL PRETTE, A.

Sobre (vivendo) nas ruas: habilidades sociais e valores de crianças e adolescentes. Psicologia: Reflexão e Crítica, Porto Alegre, v. 13, n. 3, p. 517-527, 2000.

DIAS, E. C. et al. Processo de trabalho e saúde dos trabalhadores na produção artesanal de carvão vegetal em Minas Gerais, Brasil. Cadernos de Saúde Pública, Rio de Janeiro, v. 18, n. 1, p. 269-277, 2002.

GODOY, A. S. Pesquisa qualitativa: tipos fundamentais. Revista de Administração de Empresas, São Paulo, v. 35, n. 3, p. 20-29, 1995.

IBGE - INSTITUTO BRASILEIRO DE GEOGRAFIA E ESTATÍSTICA. Pesquisa Nacional por Amostra de Domicílios: indicadores sociais. Rio de Janeiro, 2001.

LÜDKE, M.; ANDRÉ, M. E. D. Pesquisa em educação: abordagens qualitativas. São Paulo: Pedagógica e Universitária, 1986.

LUSK, M. W.; MASON, D. T. Meninos e meninas 'De Rua' no Rio de Janeiro: um estudo sobre sua tipologia. In: RIZZINI, I. (Org.). A criança no Brasil hoje: desafio para o terceiro milênio. Rio de Janeiro: Universidade Santa Úrsula, 1993. p. 153-171.

MACIEL, C.; BRITO, S.; CAMINO, L. Caracterização dos meninos em situação de rua de João Pessoa.

Psicologia: Reflexão e Crítica, Porto Alegre, v. 10, n. 2, p. 315-334, 1997.

MARQUES, W. E. U. Infâncias (pré) ocupadas: trabalho infantil, família e identidade. Brasília, DF: Plano, 2001.

MENEZES, D. M. A.; BRASIL, K. C. T. Dimensões psíquicas e sociais da criança e do adolescente em situação de rua. Psicologia: Reflexão e Crítica, Porto Alegre, v. 11, n. 2, p. 327-344, 1998.
MINAYO-GOMEZ, C.; MEIRELLES, Z.V. Crianças e adolescentes trabalhadores: um compromisso para a saúde coletiva. Cadernos de Saúde Pública, Rio de Janeiro, v. 13, n. 2, p. 135-140, 1997.

MONTANDON, C. Sociologia da infância: balanço dos trabalhos em língua inglesa. Cadernos de Pesquisa, São Paulo, v. 112, p. 33-6o, 2001.

PREFEITURA DE BELO HORIZONTE; UNIVERSIDADE FEDERAL DE MINAS GERAIS. Perfil sócio-

demográfico das crianças e adolescentes

trabalhadores do Programa Bolsa Escola de Belo Horizonte - MG-1997-2003. Belo Horizonte, 2004.

RIZZINI, I. Pequenos trabalhadores do Brasil. In: DEL PRIORE, M. (Org.). História das crianças no Brasil. São Paulo: Contexto, 2002. p. 374-406.

SERRANO, C. E. G. Eu mendigo: alguns discursos da mendicância na cidade de São Paulo. 2004.

Dissertação (Mestrado em Psicologia) - Universidade de São Paulo, São Paulo, 2004.

SILVA, A. S. et al. Crianças em situação de rua de Porto Alegre: um estudo descritivo. Psicologia: Reflexão e Crítica, Porto Alegre, v. 11, n. 3, p. 441-447, 1998.

SIROTA, R. Emergência de uma sociologia da infância: evolução do objeto e do olhar. Cadernos de Pesquisa, São Paulo, v. 112, p. 7-31, 2001.

TEVES, N. A. Representação do próprio corpo na ressocialização de jovens de rua. In: TEVES, N. A.;

RANGEL, M. (Org.). Representação social e educação: temas e enfoques contemporâneos de pesquisa.

Campinas: Papirus, 1999. p. 11-45.

TRIVIÑOS, A. N. S. Introdução à pesquisa em ciências sociais: a pesquisa qualitativa e educação. São Paulo: Atlas, 1987.

ZALUAR, A. Integração perversa: pobreza e tráfico de drogas. Rio de Janeiro: FGV, 2004. 